\title{
Laufband locomotion with body weight support improved walking in persons with severe spinal cord injuries
}

\author{
A Wernig MD, ${ }^{1} \mathrm{~S}$ Müller PhysTh ${ }^{2}$ \\ ${ }^{1}$ Department of Physiology, University of Bonn, Wilhelmstraße 31, D-5300 Bonn 1; \\ ${ }^{2}$ Rehabilitation Clinics, Langensteinbach, D-7516 Karlsbad, FRG.
}

After low transection of the spinal cord mammalian quadrupeds can be trained to walk on a driven surface indicating that coordinating neuronal circuits persist in the spinal cord segments caudal to the lesion. We trained 8 persons with incomplete spinal cord lesion on a Laufband (driven treadmill) for $1 \frac{1}{2}$ to 7 months (5 days a week, 30-60 minutes daily) starting 5 to 20 months after injury and found significant improvement in the utilisation of the paralysed limbs during locomotion. Locomotion is described in one additional patient who had trained independently on parallel bars for several years.

Five patients had complete functional paralysis in one lower limb when tested in a resting position. In EMG recordings voluntary activity (ie activity induced upon command) was absent or residual in the main flexor and extensor muscles of this limb. In contrast, during locomotion flexion and extension movements were performed and phasic EMG activity was present. In these 5 patients, and in all others reported here, skin sensibility and proprioception are preserved to different degrees in all limbs. In the course of locomotive training of 4 severely paralysed patients the initially habituating flexion reflexes could be entrained in the paralysed limbs as was the case for knee extension during stance. Subsequently, initial body weight support (BWS) of $40 \%$ could be reduced to $0 \%$. The distance covered on the Laufband $(0-104 \mathrm{~m}$ in the first week) increased significantly $(200-410 \mathrm{~m})$ in the last week of training as did speed $(0-10$ to $14-23 \mathrm{~m} / \mathrm{min}$ ). More importantly, this training subsequently allowed patients to walk on a static surface for 100 to 200 meters while voluntary activity remained absent in the paralysed limb when tested at rest.

Similar progress was achieved in the 4 less severely paralysed patients. The one patient who had trained independently on parallel bars for several years is described walking on a static surface for 40 meters with the help of a walker, though he had one completely and one near completely paralysed lower limb.

It appears that bipedal stepping with consequent knee extension and stabilisation can be taught after unilateral complete or near complete loss of voluntary activity, suggesting the manifestation of complex reflex motor patterns at the spinal level.

Key words: spinal cord injury; spastic paresis; locomotion training; body weight support; Laufband (treadmill).

\section{Introduction}

It is well known that, in human subjects who have lost voluntary movements in their lower limbs as a result of spinal cord injury, the threshold to elicit the flexion reflex (eg by stimulation of the plantar skin) is often markedly reduced. This reflex consists of a 'stepping' movement involving flexion of all the limb joints and its presence implies that the coordinating neuronal circuits have persisted in the isolated spinal cord. Moreover, in normal humans and in spinalised animals, depending on the precise phase of the gait cycle, stimulation of non nociceptive afferents facilitates activity of ipsilateral flexors or extensors and has effects on the contra- 
lateral limb as well, indicating gaiting mechanisms at spinal level driven by afferents signalling load and hip joint angles. ${ }^{1-9}$ Since the ipsilateral reflex consists of both flexion or extension we will call this 'extension/flexion $(E / F)$ reflex'. Stepping on the motor driven Laufband (treadmill) has previously been described in a variety of other mammals after complete or-in primates-incomplete low spinal transection ${ }^{1,2,10}$ and it has recently been demonstrated that the amount and quality of spinal stepping while the animal is supporting its body weight can be enhanced by prolonged training. ${ }^{11,12}$

We report here that in 8 patients with spastic paresis resulting from spinal cord injuries, prolonged Laufband training was effective in permitting or enhancing locomotive movements in limbs with complete or near complete absence of voluntary movements. Of even greater interest, we found that locomotion which is learned on the Laufband under conditions of reduced body weight can subsequently be executed on a static surface with full body weight bearing by the paralysed limb.

\section{Methods}

Nine (eight) spastic paretic patients with ages ranging from 19 to 51 years participated in the study. Five of them had complete functional paralysis in one lower limb, ie were unable to actively move this limb from a resting position (Table I) while in the other 4 patients the paralysis was less severe (Table II). In all patients skin sensibility and proprioception were present to different degrees in both limbs. One of the 5 severely paralysed patients (patient Z) had trained himself independently on parallel bars over a period of 10 years. The other patients were trained on a commercial motor driven treadmill (Laufband) which had a variable speed control. Patients were supported by a parachute harness suspended from the ceiling by a set of pulleys which allowed free movement of legs and arms, and provided a variable degree of body weight support (BWS). ${ }^{13}$ Speed was set each time to be the most comfortable for the patient. The usual training time was 30 minutes daily in a single session, 5 days a week. To quantify progress in endurance, each daily training session was started with 2 testing rounds. A testing round was defined as the maximum continuous period of time during which a patient could perform unaided bipedal stepping. For a step to be counted, one leg had to be swung past the other; when the bipedal stepping was not any longer possible, the Laufband was stopped and a 4-minute rest period followed. During this rest period the patient rested in his wheelchair which was placed on the Laufband. The distance walked and the time required for 2 consecutive testing rounds separated by 4 minutes rest were registered and later on summed and the average speed calculated (Tables III and IV). After the 2 testing rounds and another break, regular Laufband training started. During this training the therapist whenever necessary provided manual help to maintain or initiate bipedal stepping. Such help was foreward setting of the limb, ie passive hip, knee and ankle joint flexion during the swing phase, and manual knee extension and stabilisation during stance. In patient $\mathrm{C}$ during the first weeks the left ankle joint was banded with elastic bands to reduce spastic plantar flexion.

To elicite the flexor-like stepping movement in the paralysed limb the patient was instructed to put load (body weight) onto the fully extended limb during stance and to deload and shift body weight onto the contralateral limb shortly before swing. Therefore, care was also taken that the arm support provided by a lateral frame was used merely to maintain balance and not to provide additional body weight support. Elicitability and endurance of the stepping movements to some degree correlated with the spastic muscle tone present, which in some patients varied from time to time. Barefoot walking and pinching of the limb facilitated stepping and were occasionally applied during the first weeks of training.

BWS, initially set at $40 \%$, was reduced to 20 and $0 \%$ either when a plateau in endurance became visible or when less BWS allowed stepping with more pronouncd hip flexion (see above).

After several weeks of Laufband training 
Table I Ratings of voluntary muscle activity and maximal force in 5 spastic paretic patients 16,16 , $18,17 \frac{1}{2}$ months and 10 years after traumatic focal (A, B, D and Z) or postinflammatory diffuse (C) spinal cord lesion. Ratings were performed after completion of the training period with the patient's limbs and body in defined positions. ${ }^{14}$ The following scoring system was used: 0 -no voluntary muscle activity detectable; 1 -voluntary muscle contraction visible but without movement; 2 -some movement, not against gravity; 3-full range of movement against gravity; 4-full movement, plus maintenance of position against moderate applied force; 5-like 4, movement and maintenance against maximal applied force. In all patients limb proprioception and skin sensibility were preserved to different degrees

\begin{tabular}{|c|c|c|c|c|c|c|c|c|c|c|}
\hline & \multicolumn{2}{|c|}{ Patient A } & \multicolumn{2}{|c|}{ Patient B } & \multicolumn{2}{|c|}{ Patient $\mathrm{C}$} & \multicolumn{2}{|c|}{ Patient D } & \multicolumn{2}{|c|}{ Patient Z } \\
\hline & left & right & left & right & left & right & left & right & left & right \\
\hline \multicolumn{11}{|l|}{ Trunk } \\
\hline M. obliquus abd. ext. & 2 & 2 & 4 & $3-4$ & $1-2$ & 2 & 1 & 1 & $0^{1}$ & $0^{1}$ \\
\hline M. obliquus abd. int. & 1 & 1 & 4 & $3-4$ & $1-2$ & 2 & 1 & 1 & 0 & 0 \\
\hline M. rectus abd. & 2 & $2-3$ & $2-3$ & $2-3$ & $1-2$ & 2 & 1 & 1 & $0^{1}$ & $0^{1}$ \\
\hline M. quad. lumb. & 0 & 1 & 0 & 1 & $1-2$ & 2 & 1 & 1 & 0 & 0 \\
\hline \multicolumn{11}{|c|}{$1=$ upper segments can be activated } \\
\hline \multicolumn{11}{|l|}{ Lower limb } \\
\hline M. iliopsoas & 0 & $3-4$ & 0 & 4 & 0 & 3 & 0 & 2 & 0 & 0 \\
\hline M. sartorius & 0 & $3-4$ & 0 & 4 & 0 & $3-4$ & 0 & 2 & 0 & 0 \\
\hline M. glutaeus med. & 0 & 1 & 0 & $2-3$ & 0 & 3 & 0 & 0 & 0 & 0 \\
\hline M. tensor fasc. lat. & 0 & 2 & 0 & $2-3$ & 0 & 3 & 0 & $1-2$ & 0 & 0 \\
\hline M. adductores & 0 & $3-4$ & 1 & 2 & 0 & $3-4$ & 1 & 1 & 0 & 0 \\
\hline M. quadriceps fem. & 0 & $3-4$ & 0 & $4-5$ & 0 & $3-4$ & 0 & 2 & 0 & 0 \\
\hline M. glutaeus max. & 0 & $1-2$ & 1 & 0 & 0 & $2-3$ & 0 & 0 & 0 & 0 \\
\hline Hamstrings & 0 & $3-4$ & 0 & 2 & 0 & $4-5$ & 0 & $2-3$ & 0 & 0 \\
\hline M. tibialis ant. & 0 & $4-5$ & 0 & 2 & 0 & 5 & 0 & $3-4$ & 0 & 2 \\
\hline M. triceps surae & 0 & $3-4$ & 0 & $2-3$ & 0 & $4-5$ & 0 & 0 & 0 & 0 \\
\hline \multicolumn{11}{|l|}{ Level of spinal } \\
\hline cord lesion & \multicolumn{2}{|c|}{$\mathrm{C} 5$} & \multicolumn{2}{|c|}{$\mathrm{C} 7$} & \multicolumn{2}{|c|}{$(\mathrm{C} 6-7)$} & \multicolumn{2}{|c|}{ C6 } & \multicolumn{2}{|c|}{ T6 } \\
\hline Patients ages (years) & \multicolumn{2}{|c|}{19} & \multicolumn{2}{|c|}{24} & \multicolumn{2}{|c|}{23} & \multicolumn{2}{|c|}{20} & \multicolumn{2}{|c|}{32} \\
\hline
\end{tabular}

Table II Functional ratings of major lower limb muscles in 4 spastic paretic patients

\begin{tabular}{|c|c|c|c|c|c|c|c|c|}
\hline & \multicolumn{2}{|c|}{ Patient E } & \multicolumn{2}{|c|}{ Patient F } & \multicolumn{2}{|c|}{ Patient G } & \multicolumn{2}{|c|}{ Patient $\mathrm{H}$} \\
\hline & left & right & left & right & left & right & left & right \\
\hline M. iliopsoas & 0 & $3-4$ & $2-3$ & $2-3$ & 3 & $2-3$ & 1 & $2-3$ \\
\hline M. sartorius & $1-2$ & 4 & $2-3$ & 3 & 2 & 2 & $2-3$ & $4-5$ \\
\hline M. glutaeus med. & 1 & $2-3$ & 1 & 1 & 1 & 1 & 1 & $3-4$ \\
\hline M. tensor fasc. lat. & 0 & $3-4$ & $1-2$ & $2-3$ & $2-3$ & $2-3$ & 1 & $2-3$ \\
\hline M. adductores & $2-3$ & 4 & 3 & 3 & $2-3$ & $2-3$ & $1-2$ & 5 \\
\hline M. quadriceps fem. & $4-5$ & 5 & 2 & $2-3$ & 4 & 4 & $0^{*}$ & 5 \\
\hline M. glutaeus max. & 0 & $2-3$ & 1 & 1 & 0 & 1 & 1 & $1-2$ \\
\hline Hamstrings & 1 & $3-4$ & 1 & 2 & $1-2$ & $1-2$ & 1 & 2 \\
\hline M. tibialis ant. & $3-4$ & 5 & 4 & $3-4$ & 4 & $3-4$ & 1 & $4-5$ \\
\hline M. triceps surae & $2-3$ & $4-5$ & 3 & 3 & $1-2$ & $1-2$ & $0^{*}$ & 4 \\
\hline Level of spinal lesion & \multicolumn{2}{|c|}{$\mathrm{T} 5$} & \multicolumn{2}{|c|}{$\mathrm{C} 4-5$} & \multicolumn{2}{|c|}{$\mathrm{T} 12$} & \multicolumn{2}{|c|}{$\mathrm{T} 11$} \\
\hline Patient's age (years) & \multicolumn{2}{|c|}{28} & \multicolumn{2}{|c|}{50} & \multicolumn{2}{|c|}{51} & \multicolumn{2}{|c|}{26} \\
\hline
\end{tabular}

* = poorly time-locked extensor mass movements 


\section{Wernig and Müller}

Table III Locomotive capabilities and training programme of 5 spastic paretic persons. Laufband locomotion was initially performed with $40 \%$ BWS which was gradually reduced to $0 \%$; data for distance and speed represent the sum of 2 consecutive testing rounds separated by 4 minutes rest (see Methods); the 2 values given represent the range within a week. Data for walking on a static surface were taken from the last 3 weekly testing rounds towards the end of the indicated period of Laufband training. Values for speed and maximal distance are taken from the same session. There was a break of 1-4 minutes after each $25 \mathrm{~m}$ of walking. Owing to paralysis of arm muscles, patient $\mathrm{A}$ used a hand rail and was aided by the therapist to maintain balance during walking, while the other patients used a walker (patients $\mathrm{C}$ and $\mathrm{Z}$ ) or 2 canes (patients $\mathrm{B}$ and $\mathrm{D}$ ), one attached to the arm (patient B). Staircase walking tested over 15 steps (upwards and downwards) was aided by the therapist in patient $\mathrm{A}$. Patient $\mathrm{Z}$ had trained independently on parallel bars over a period of several years

\section{Patient A Patient B Patient C Patient D Patient Z}

\begin{tabular}{lccccc}
\hline $\begin{array}{l}\text { Laufband locomotion } \\
\text { Beginning after lesion (months) }\end{array}$ & $8 \frac{1}{2}$ & $5 \frac{1}{2}$ & 12 & $15 \frac{1}{2}$ & - \\
$\begin{array}{l}\text { Duration of training (months) } \\
\text { Distance (m): }\end{array}$ & 5 & 7 & 6 & 2 & - \\
$\quad$ first week (40\% BWS) & $32-104$ & $0-36$ & 0 & $0-40$ & - \\
$\quad$ last week (0\% BWS) & $200-310$ & $230-410$ & $240-290$ & $260-420$ & - \\
Speed (m/min): & $7-8$ & $0-10$ & 0 & $0-18$ & - \\
$\quad$ first week (40\% BWS) & $14-16$ & $17-23$ & $16-18$ & $18-21$ & - \\
$\quad$ last week (0\% BWS) & $150^{*}$ & 105 & 200 & 150 & 40 \\
Walking on static surface with canes or a walker after the period of Laufband training & \\
Maximal distance (m) & $10^{*}$ & 9 & 6 & 10 & 6 \\
Speed (m/min) & yes* & yes & no & yes & yes \\
Stair case walking & C5 & C7 & $($ C6-7) & C6 & T6 \\
Level of spinal lesion & & & & &
\end{tabular}

*balance supported by therapist.

Table IV Locomotive capabilities of 4 incompletely paralysed spastic patients $(\mathrm{E}-\mathrm{H})$ at the beginning and end of prolonged Laufband training. Walking on static surface was monitored during the whole period in patient $\mathrm{H}$ but only for the last 1 and 2 months in patients $\mathrm{E}$ and $\mathrm{F}$. Speed of walking was tested over a distance of $150 \mathrm{~m}$ with a break of 4 minutes after each $50 \mathrm{~m}$

\begin{tabular}{|c|c|c|c|c|c|c|c|c|}
\hline & \multicolumn{2}{|c|}{$\begin{array}{l}\text { Patient } E \\
\text { beginning end } \\
\text { of training }\end{array}$} & \multicolumn{2}{|c|}{$\begin{array}{l}\text { Patient } F \\
\text { beginning end } \\
\text { of training }\end{array}$} & \multicolumn{2}{|c|}{$\begin{array}{l}\text { Patient } G \\
\text { beginning end } \\
\text { of training }\end{array}$} & \multicolumn{2}{|c|}{$\begin{array}{l}\text { Patient } \mathrm{H} \\
\text { beginning end } \\
\text { of training }\end{array}$} \\
\hline $\begin{array}{l}\text { Laufbaud training } \\
\text { Beginning after lesion } \\
\text { (months) }\end{array}$ & \multirow{2}{*}{\multicolumn{2}{|c|}{7}} & \multirow{2}{*}{\multicolumn{2}{|c|}{5}} & \multicolumn{2}{|c|}{20} & \multicolumn{2}{|c|}{11} \\
\hline \multirow{4}{*}{$\begin{array}{l}\text { Training period (months) } \\
\text { distance }(\mathrm{m}) \\
\text { speed }(\mathrm{m} / \mathrm{min}) \\
\text { BWS }(\%)\end{array}$} & & & & & & & & \\
\hline & 140 & 300 & 150 & 600 & 193 & 350 & 100 & 500 \\
\hline & 12 & 15 & 9 & 12 & 12 & 16 & 10 & 17 \\
\hline & 20 & 0 & 40 & 0 & 40 & 40 & 20 & 0 \\
\hline $\begin{array}{l}\text { Walking }(150 \mathrm{~m}) \\
\text { speed }(\mathrm{m} / \mathrm{min})\end{array}$ & 15 & 20 & 7 & 13 & 0 & $4^{*}$ & $4^{* *}$ & 17 \\
\hline
\end{tabular}

*Patient $G$ was tested once after the end of the training period and walked $20 \mathrm{~m}$ with intermissions.

**Aided by therapist. 

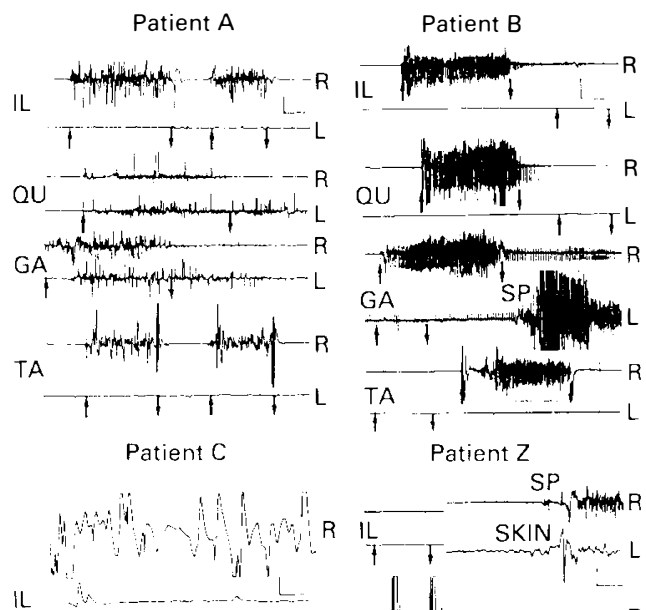

it
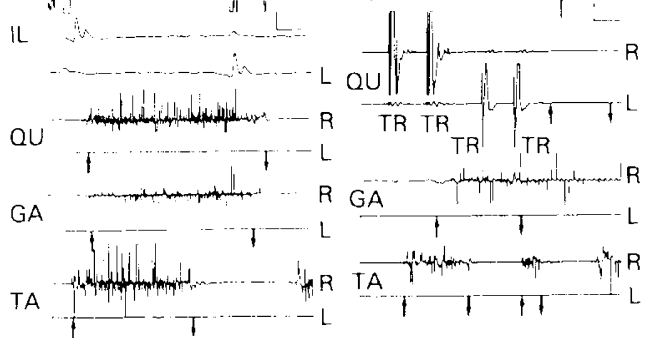

Figure 1 EMG recordings during resting (horizontal supine) position of maximal voluntary activity from right $(\mathrm{R})$ and left $(\mathrm{L})$ lower limb muscles in patients $\mathrm{A}, \mathrm{B}, \mathrm{C}$ and $\mathrm{Z}$. Records were taken after training period which lasted for several months (Table III). Arrows indicate verbal commands to activate $(\uparrow)$ and relax $(\downarrow)$ corresponding muscles in both limbs simultaneously or in one limb at a time (patient B; IL in patient $\mathrm{Z}$ ). Patient $\mathrm{A}$ : While activity in muscles of the right limb appears time locked, activity in QU and GA in the left limb cannot be stopped upon command and is absent in IL and TA. Scale bars: $200 \mu \mathrm{V}$ (GA), $500 \mu \mathrm{V}$ (IL, QU), $1 \mathrm{mV}$ (TA) and $1 \mathrm{sec}$. Patient B: no time locked evoked activity is seen in left muscles (lower traces) except for a slight increase in background activity in GA; SP: evoked multijoint extensor spasticity. Activity is time locked in right muscles. Scale bars: $100 \mu \mathrm{V}$ (left GA), $500 \mu \mathrm{V}$ (other muscles) and $3 \mathrm{sec}$. Patient C: while there is residual voluntary activity in left IL, other muscles in the left limb are silent. Scale bars: $100 \mu \mathrm{V}$ (IL, TA), $\quad 500 \mu \mathrm{V}$ (QU, GA), $10 \mathrm{~ms}$ (IL), and $1 \mathrm{sec}$ (QU, GA, TA). Patient $\mathrm{Z}$ : there is time locked voluntary activity in right TA and induceable but uncontrollable activity in GA. There is no voluntary activity in other muscles (arrows). In the right limb the patient could occasionally induce a multijoint flexion pattern while in a horizontal in patients $A, B, C$ and $G$, but earlier in the other patients, walking on a static surface was attempted and performed once a week, thus replacing one Laufband session. Different categories of support were successively provided during overground walking: initially, when necessary, the patient was supported by 2 therapists, one on each side; as soon as possible this was changed to support by a handrail plus support for balance by one therapist; later a handrail plus a cane, and two canes or a walker were supplied. During the weekly test rounds rest periods of 1-4 minutes were kept after each 25 metres of walking in patients $A-D$ and $\mathrm{Z}$, and 4 minutes after 50 metres in patients E-H.

Apart from Laufband training and overground walking, patients participated in the regular rehabilitation programme provided in the clinic.

Joint angle movements during locomotion on the Laufband and on firm, static ground were measured from single frames of video films (25 frames per second). Joint axes (hip, knee and ankle) and reference points (shoulder, foot) marked on the patients with adhesive labels were transferred from the video monitor onto lucite foils and via a digitising tablet to a computer for joint angle calculation. Trunk and hip joint angles were defined as deviations of the trunk or the femur from a vertical line, positive indicating forward. Knee joint angle was measured between femur and tibial axes.

EMG recordings were performed with conventional needle and surface electrodes using Medelec-Ms 20 and Neuropack-4 amplifiers (cut-off frequencies: $10 \mathrm{~Hz}$, $20 \mathrm{kHz}$ in patients $\mathrm{A}, \mathrm{C}, \mathrm{Z}$ in Figure 1; and $10 \mathrm{~Hz}, 5 \mathrm{kHz}$ in patient $\mathrm{B}$ in Figure 1 and in patient $\mathrm{Z}$ in Figure 2). During rest, recordings from ipsi- and contralateral muscles were performed simultaneously with the

position (SP, right IL); in the left IL the effect of moderate skin irritation (which too evoked a flexor-reflex) is demonstrated (SKIN, lower trace, not simultaneously recorded with the upper trace). TR = tendon reflex. Scale bars: $200 \mu \mathrm{V}$ for IL, QU and GA, $500 \mu \mathrm{V}$ for TA and $1 \mathrm{sec}$. 
patients in a horizontal supine position. During the assessment of voluntary activity in single muscles, verbal commands were given to perform the corresponding movement, eg flexion or extension at a single joint (arrows in Figure 1). The patients were instructed not to induce multijoint flexor or extensor mass movements during this time, although such mass movements could occassionally be intentionally induced by all patients (SP in Figure 1; see Results).

Transcranial magnetic field stimulation was performed with a Novametrix Magstim 200 with $100 \%$ stimulus intensity (maximal 1,5 Tesla); stimuli were applied while the patients attempted to evoke maximal voluntary muscle activity.

(Abbreviations used: $\mathrm{IL}=\mathrm{m}$. iliopsoas; $\mathrm{QU}=\mathrm{m}$. quadriceps; $\mathrm{ST}=\mathrm{m}$. semitendinosus; $\mathrm{GA}=\mathrm{m}$. gastrocnemius; $\mathrm{TA}=\mathrm{m}$. tibialis anterior; $\mathrm{SW}=$ swing phase of gait; STA $=$ stance phase of gait; $\mathrm{BWS}=$ body weight support.)

\section{Results}

\section{Locomotion in the absence of voluntary} limb movement

The 4 patients (A-D) with functionally complete paralysis in one limb (Table I) learned to walk on a static surface after prolonged periods of training although active limb movement in the resting position remained absent. One patient $(Z)$ who had trained himself over a period of 10 years, could walk over a distance of 40 metres although voluntary activity was completely missing in one and was residual in the other limb (Table I). Table I gives the current ratings of muscle function for several major limb and trunk muscles in defined resting positions. ${ }^{14}$ These have not been changed by training in the completely paralysed (left) limbs but had significantly improved in the course of training in the less paretic (right) limbs. Accordingly, none of the patients can perform sufficient active hip flexion or knee extenson in the left limb to allow any movement against gravity. Obviously during locomotion, movement of the paralysed limbs is initiated and maintained by spinal reflexes or motor programmes. Typically, to start locomotive movements the paralysed

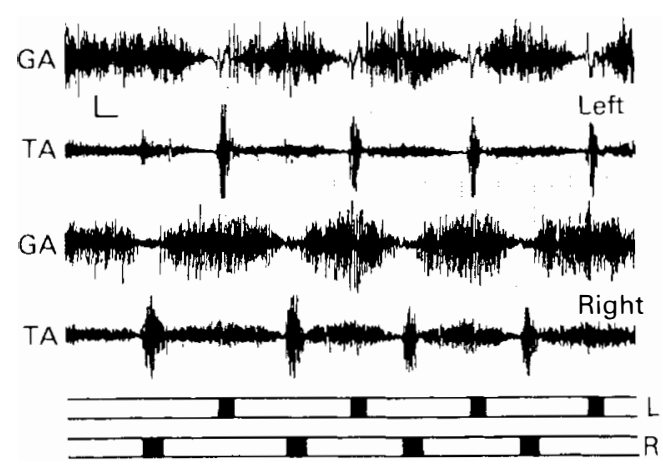

Figure 2 Simultaneous EMG recordings from main flexor and extensor muscles in the lower limbs of patient $\mathrm{Z}$ during walking on a static surface. In patient $Z$ phasic activities were most pronounced. Also indicated are stance (open bars) and swing (black bars) phases in the right (R) and left (L) limb. Scale bars: $100 \mu \mathrm{V}$ and $1 \mathrm{sec}$.

limb extended in the hip joint to more than $180^{\circ}$ has first to be fully loaded and then-by shifting body weight onto the contralateral limb-deloaded.

Electromyographic recordings in the resting supine position revealed that voluntary activity was absent from most muscles tested in the paralysed limb, while different kinds of residual activity were present in others (Fig 1). Most strikingly, in patient $\mathrm{Z}$ there was a little activity in the right limb but none in the left. Interestingly, in some muscles (left QU and GA in patient A, right GA in patient Z) activity started upon command or with some delay but could not be stopped upon a command even within seconds: this type of activity has been described previously in spastic paretic limbs and might reflect residual voluntary activity. ${ }^{15,16}$ All patients can initiate spastic extensor orless frequently-flexor multijoint mass movements while in a resting horizontal position (eg patient $\mathrm{B}$ left $\mathrm{GA}$, patient $\mathrm{Z}$ right IL in Figure 1), which we do not consider to be voluntary movements because they are not readily evokable, poorly time locked and easily exhaustible. Such movements are apparently initiated and facilitated by passive stretch of the paralysed limb, usually together with other manoeuvres like activation of the contralateral limb and muscles proximal to the lesion 
and have been described in patients with residual descending connections. ${ }^{16}$

In patient $\mathrm{D}$ no time locked voluntary activity was detectable in the main flexors and extensors of the left lower limb (data not shown). In the less severely affected legs in patients $\mathrm{A}, \mathrm{B}, \mathrm{C}$ and $\mathrm{D}$ (right leg) voluntary activity could be evoked and was time locked (arrows in Figure 1).

Transcranial magnetic field stimulation of motor cortical areas in patient A evoked small signals in left GA and QU (smaller than in the contralateral muscles), indicating remaining descending connections in the left half of the spinal cord. In patients D and $\mathrm{Z}$ transcranial stimulation evoked activity in the right but not the left TA, as was the case during attempts of voluntary activation (Fig 1).

\section{Quantitative parameters of training and locomotion}

In 3 patients ( $B, C$ and $D)$ stepping on the Laufband was achieved only after several training sessions in which the therapist moved the paralysed limb in a stepping pattern. Similarly, even with automatic stepping, knee extension had to be performed passively for some time (several days to weeks) before it occurred unaided.

There was a significant increase in speed and duration (distance) of Laufband locomotion over the course of 2-7 months (Table III), and BWS could be reduced from the initial $40 \%$ to $20 \%$ and finally $0 \%$. Overground walking was initially aided by the therapists, but this help was gradually reduced (see Methods). Patients B, C and D eventually could walk unaided for 100 to 200 metres using 2 walking sticks or a walking frame (walker) (Table III). Patient $\mathrm{Z}$ with little voluntary activity in one limb and none in the other (Table I, Fig 1), who had trained over several years on parallel bars, walked for about 40 metres with the help of a walker. Continuous locomotion is usually terminated by failure of the flexion and/or extension pattern, either because of increased extensor spasticity or apparently reduced muscle activity; in patient $B$ the latter was often triggered by irritation of the urinary bladder. Patients $\mathrm{A}, \mathrm{B}, \mathrm{D}$ and $\mathrm{Z}$ could perform staircase walking, hip flexion often being sufficient to allow each foot to be placed one step higher than the other.

\section{EMG recordings during locomotion}

In contrast to the small or absent voluntary activity, muscles in the paralysed limbs become phasically active during stepping movements on firm ground. This is best visible in patient $\mathrm{Z}$ (Fig 2) who besides coactivations shows alternating activities of flexors and extensors. Recordings from individual patients vary in several respects (the relative amount and duration of activity in each muscle, amount of coactivation of antagonists, amount of clonic activity), but in general all show phasic activity patterns.

\section{Joint angle measurements during locomotion}

These showed marked hip flexion and knee extension movements against gravity (Fig 3), while several features deviate from normal and indicate spastic gait. ${ }^{13,17,18}$ Trunk angles (data not shown), which are normally zero (trunk vertical) to positive (trunk anteroflexed), become - at the onset of swing-temporarily negative (as much as $5-10^{\circ}$ in patient $\mathrm{Z}$ ), thus presumably facilitating hip flexion by causing stretch reflex activity of IL muscles. Hip flexion (Fig 3) is in the range of normal (about $\left.30^{\circ}\right)^{11}$ and often larger than normal for individual steps. As is typical for spastic gait knee joint angle is more flexed than normal prior to foot contact in patients $\mathrm{A}, \mathrm{B}$ and $\mathrm{Z}$ thereby reducing stride length in relation to the degree of hip flexion occurring during swing. In contrast, knee extension during stance can be performed by all patients.

\section{Laufband training in persons with less} severe spastic paresis

All 4 patients with different degrees of spastic paresis in both limbs (Table II) exercised on the Laufband and subsequently improved their locomotive capacity (Table IV). This improvement was due to better hip flexion during swing and knee stabilisation during stance. In patients with a high spastic muscle tone (patients E,F) BWS 

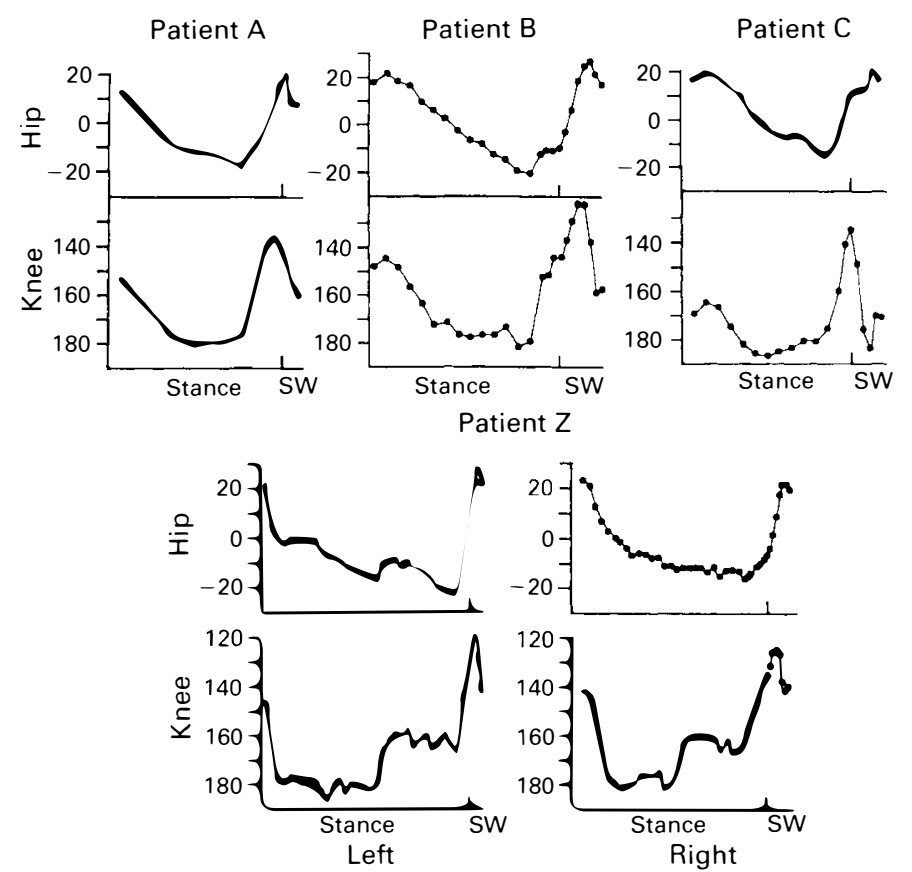

Figure 3 Joint angle movements measured from video films of hip and knee joints during single strides on a firm surface in the left or both (Patient Z) paralysed lower limbs. Hip angle is defined by a vertical line and the femur; knee angle between tibia and femur. Though active joint movement is absent in a resting position, there are normal degrees of hip and knee flexion and knee extension present during locomotion in all patients. Swing phases (SW) during lift off and touch down of the foot are relatively short, in part due to dragging of the foot over ground (patient $\mathrm{A}$ ). In patient $\mathrm{Z}$ sagging of the knee occurs long before the onset of SW. In patient $\mathrm{C}$ the left ankle joint was stabilised by elastic bands. $\mathrm{SW}=$ stance phase. Time scale: during stance, the time interval between points is $500 \mathrm{~ms}$ (patient A) and $250 \mathrm{~ms}$ (other patients), during and before SW $125 \mathrm{~ms}$. Accordingly, stride duration is between $4-5 \mathrm{sec}$ in patients A, B and C but around $8 \mathrm{sec}$ in patient $\mathrm{Z}$.

initially was helpful in retarding the development of paralysing extensor spasticity, thus allowing more hip flexion. ${ }^{13}$ Patient $\mathrm{H}$ with some voluntary activity in the left limb (especially sartorius, see Table II) had before completed a conventional rehabilitation programme after which she walked for several meters with the help of 2 canes but practically no use of the paralysed limb. This patient learned to readily evoke the $\mathrm{E}$ and $F$ patterns and utilise them during locomotion together with the remaining voluntary activity; eventually the flexion pattern even became evokable from a standing position with both limbs in parallel, simply by shifting body weight first to the left and then to the right limb (see above).
A similar phenomenon was very rarely present in patient $\mathrm{A}$ when hip flexion in the left limb was evokable by 'stepping on the site' ie lifting and consequently loading the right limb.

\section{Discussion}

The present results indicate that despite the near complete loss of time locked voluntary movements in one (or both) limbs due to spinal cord injury, patients can learn to perform bipedal stepping with joint stabilisation and body weight bearing. Possibly, even unilaterally remaining descending connections coordinate the extension and flexion $(E$ and $F)$ pattern in each limb and 
manage interlimb coordination. It has been known for some time that non primate adult spinalised animals can be made to walk on a driven treadmill and walking capacity can be enhanced by training. ${ }^{11,12}$ This indicates that in such animals spinal circuits together with limb afferents suffice to accomplish stepping on a moving surface. In primates, stepping on the treadmill could not be elicited after complete spinal transection but was entrainable with sparing, even unilaterally, of parts of the ventral white matter. ${ }^{10,19}$ This is in line with our preliminary observation that in 3 completely paralysed patients the full stepping pattern, ie flexion and extension, could not be entrained within several weeks, although in one patient the flexion pattern was readily evokable during Laufband locomotion.

Several findings from spinal and decerebrate animals proved to be relevant to our training regimen ${ }^{1,2,4,5,20}$ : initiation and maintenance of stepping in the paralysed limb was usually possible only when the knee joint was fully extended during stance, the hip joint was extended to more than $180^{\circ}$ after mid stance and the limb became deloaded after previously bearing the full body weight. The patient who had trained independently over several years has developed the same strategies for locomotion. Noteworthy in this respect is the fact that some level of reflex hyperactivity is beneficial to eliciting stepping behaviour, and antisplastic medication could block it. Apparently $\mathrm{E}$ and $\mathrm{F}$ reflexes function best in patients with some 'background spasticity'. Severe extensor spasticity on the other hand also blocked flexion movements and thus terminated locomotion as did the cessation of flexion reflexes.

It will be necessary in future studies to determine the optimal time to start the training. In a screening programme involving chronic (more than 5 years after spinal cord injury) paretic patients we found that in 3 out of 6 comparable patients the flexion pattern was evokable within minutes of Laufland walking and body weight support (A Wernig, S Müller, A Nanassy, unpublished) indicating that successful training might be started years after the initial spinal cord lesion.

The training which we have described has allowed patients with unilateral limb paralysis to walk short distances, to bear their body weight fully without knee stabilising braces and to climb stairs while needing only a handrail and one cane. Without this training the patients would be more bound to the wheelchair and at best walk with anteroflexion of the trunk, putting maximal body weight onto the supporting canes and circumducting the paralysed limb which needs to be supported by long braces. Less severely paralysed patients significantly improved their locomotive capacity mainly by improving hip flexion and knee extension and stabilisation. In addition, Laufband locomotion has the potential to improve muscle strength and enhance cardiorespiratory fitness. It therefore appears that Laufband locomotion is of benefit for spastic paraplegic persons with quite different degrees of paralysis.

\section{Acknowledgements}

We thank Frau Elke Cagol for helping to exercise the patients. Dr Wunderle (Karlsbad) and Drs Dengler and Schubert (Bonn) kindly performed the EMG recordings. Transcranial magnetic field stimulations were performed by Drs Dengler and Schubert (Bonn) and Dr Dietz (Freiburg). Drs Harms, Stoltze and Nanassy (Karlsbad) continuously encouraged and supported our work.

\section{References}

1 Grillner S (1981) Control of locomotion in bipeds, tetrapods, and fish In: Brookhart JE, Mountcastle VB, Brooks VB, Geiger SR, editors. Handbook of Physiology, Section 1, Vol. 2, Part 2. American Physiological Society, Bethesda, Md: 1127-1236.

2 Gossard J-P, Hultborn H (1991) On the organization of the spinal rhythm generation in locomotion. In: Wernig A, ed. Plasticity of Motoneuronal Connections. Elsevier, Amsterdam.

3 Schomburg ED (1990) Spinal sensorimotor systems and their supraspinal control. J Neurosci Res 7 : 265-340.

4 Andersson O, Grillner S, Lindquist M, Zomlefer M (1978) Peripheral control of the spinal pattern generators of locomotion in cat. Brain Res 150: 625-630. 
5 Conway BA, Hultborn H, Kiehn O (1987) Proprioceptive input resets central locomotor rhythm in the spinal cat. Exp Brain Res 68: 643-656.

6 Dietz V, Quintern J, Boos G, Berger W (1986) Obstruction of the swing phase during gait: phase-dependent bilateral leg muscle coordination. Brain Res 384: 166-169.

7 Duysens J, Trippel M, Horstmann GS, Dietz V (1990) Gating and reversal of reflexes in ankle muscles during human walking. Exp Brain Res 82: 351-358.

8 Herman R, Seif-Naraghi A, Fuller J, Yapp R, D'Luzansky S (1991) Phase dependent reflexes during sterotyped movements in man: cycling and locomotion. In: Wernig A, editor. Plasticity of Motoneuronal Connections. Elsevier, Amsterdam.

9 Yang JF, Stein RJ (1990) Phase-dependent reflex reversal in human leg muscles during walking. J. Neurophysiol 63: 1109-1117.

10 Eidelberg E, Walde JG, Nguyen LH (1991) Locomotor control in macaque monkeys. Brain 104: $647-663$.

11 Lovely RG, Gregor RJ, Roy RR (1986) Effects of training on the recovery of full-weight-bearing stepping in the spinal adult cat. Exp Neurol 92: 421-435.

12 Barbeau H, Rossignol S (1987) Recovery of locomotion after chronic spinalization in the adult cat. Brain Res 412: 844-895.

13 Visintin M, Barbeau H (1989) The effects of body weight support on the locomotor pattern of spastic patients. Can J Neurol Sci 16: 315-325.

14 Kendall HO, Kendall FP, Wadsworth GE (1971) Muscles - Testing and Function. 2nd ed. The Williams and Wilkins Company, Amsterdam.

15 Sahrmann SA, Norton BJ (1977) The relationship of voluntary movements to spasticity in the upper motor neuron syndrome. Ann Neurol 2: 460-465.

16 Dimitrijevic MR, Dimitrijevic Meta M, Faganel J, Sherwood AM (1984) Suprasegmentally induced motor unit activity in paralyzed muscles of patients with established spinal cord injury. Ann Neurol 16: 216-221.

17 Knutsson E (1985) Studies of gait control in patients with spastic paresis. In: Delwaide PJ, Young RR, editors. Clinical Neurophysiology in Spasticity. Elsevier, Amsterdam: 175-183.

18 Conrad B, Benecke R, Meinck HM (1985) Gait disturbances in paraspastic patients. In: Delwaide PJ, Young RR, editors. Restorative Neurology, Vol. 1. Clinical Neurophysiology in Spasticity. Elsevier, Amsterdam: 1855-174.

19 Eidelberg E (1981) Consequences of spinal cord lesions upon motor function with special reference to locomotor activity. Prog Neurobiol 17: 185-202.

20 Pearson KG, Duysens J (1976) Function of segmental reflexes in the control of stepping in cockroaches and cats. In: Herman RM, Grillner S, Stein PSG, Stuart DG, editors. Neural Control of Locomotion. Plenum Press, New York: 519-537. 